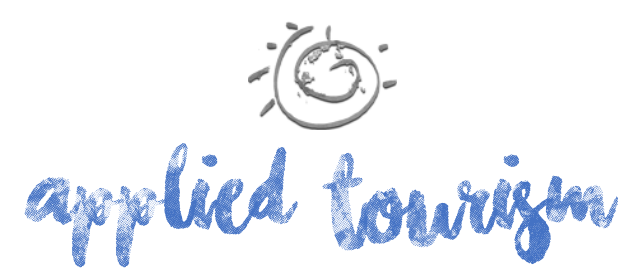

Volume 2, número 1,2017, p. 128-148

\title{
INDICADORES DE AVALIAÇÃODE GOVERNANÇA EM DESTINOS TURÍSTICOS- uma análise da aplicabilidade dos modelos propostos
}

\section{Doris Van de Meene Ruschmann}

PhD em Ciências da Comunicação - Turismo

Universidade do Vale do Itajaí

doris@ruschmannconsultores.com.br

Francisco Antonio dos Anjos

PhD em Engenharia de Produção / Gestão Ambiental

Universidade do Vale do Itajaí anjos@univali.br

Marcos Arnhold Junior

Mestre em Turismo e Hotelaria

Universidade do Vale do Itajaí marcosjunior@univali.br

Recebido: 17 de junho, 2016

Aprovado: 17 de novembro, 2016

\section{RESUMO}

Este estudo tem como objetivo identificar os conceitos relacionados à governança do turismo e, a partir dessa base, são relacionados diferentes modelos de indicadores propostos e tipologias aplicadas à governança, que ensaiam a construção de uma ferramenta de avaliação para a mensuração da governança do turismo. Este trabalho utilizou-se de pesquisa bibliográfica para identificar indicadores de avaliação encontrados na literatura sobre governança. Como resultado, foram identificados quatro estudos, dois deles relacionados com a governança do turismo, um com a governança pública e outro relacionado com as tipologias de governança aplicadas ao turismo. Esta análise também percebe a necessidade de um instrumento de real aplicabilidade que possa avaliar a governança do turismo em diferentes destinos.

Palavras Chave: Turismo. Governança. Indicadores de Avaliação de Governança. 


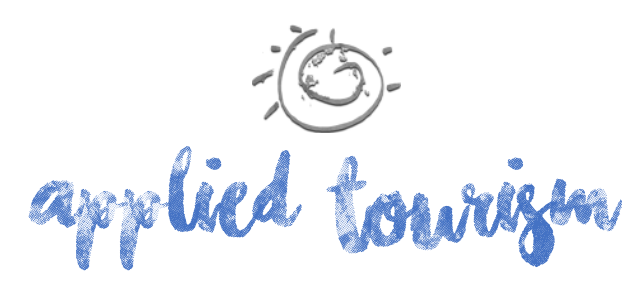

Volume 2, número 1,2017, p. 128-148

\section{INTRODUÇÃO}

Hoje em dia o modelo de gestão pública tem sido aberto a novas maneiras de governar. A construção de políticas públicas que garantam benefícios para a maior parte da sociedade é uma busca constante, seja pelo Estado, seja por líderes empresariais e da sociedade civil organizada.

As políticas públicas devem ser entendidas como aquelas ações que um determinado governo decide implementar, a fim de atender a uma demanda pública ou resolver um problema, lembrando que esta escolha sofre forte influência política no interesse dos vários sectores que podem por ela serbeneficiadas. (Oliveira \& Pisa, p.1264-65, 2015)

Quando essas políticas afetam a participação de outros atores da sociedade (stakebolders), há uma busca de consenso sobre a definição de objetivos voltados para alcançar resultados benéficos para todos os participantes. O incentivo para a sociedade civil organizada a participar no processo de gestão pública permite a pesquisa para o desenvolvimento respeitando a vontade do povo (Hall, 2011). No ambiente desta participação para a escolha das formas políticas temos o conceito de governança, ganhando um significativo grau de importância, tanto em estudos acadêmicos como nas práticas institucionais. Governança é o resultado de uma política pública repensado a fim de permitir a convergência de ações e objetivos. No Brasil, esse pensamento vem com a promulgação da Constituição de 1988, que permitiu a criação de um Estado democrático de direito, permitindo aos cidadãos exercerem controle na administração pública e escolherem as políticas a serem implementadas, prezando pela ética, integridade, transparência e prestação de contas (Oliveira \& Pisa, 2015).

Esse modelo de gestão tem um maior grau de complexidade devido à natureza participativa, tendo a singularidade do Estado como condutor da linha de processo. Governança não se restringe aos aspectos gerenciais e administrativos do Estado, nem ao bom funcionamento do aparelho de Estado, mas aos padrões de articulação e cooperação entre atores sociais e políticos e arranjos institucionais que coordenam e regulam as operações dentro e através das fronteiras do sistema econômico (Santos, 1997), incluindo não só os mecanismos 


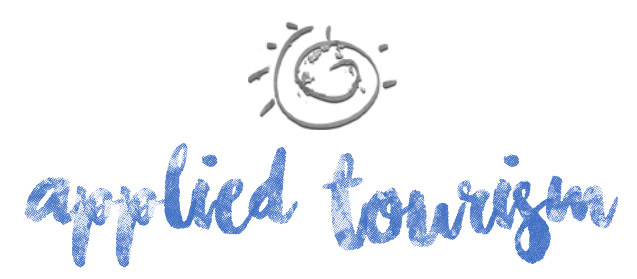

Volume 2, número 1,2017, p. 128-148

tradicionais de agregação e articulação de interesses, tais como partidos políticos e grupos de pressão, mas também as redes sociais informais.

Governança seria uma forma distinta de governo, com diferentes causas, manifestações e resultados, que levam a atividades com alta variação no formato, conteúdo e também no seu alcance, e que pode assumir a forma de um fenômeno ou até mesmo ser organizado por um quadro analítico. Assim, a governança acaba por ter um conceito muito amplo atualmente, mas também pode ser considerada um conceito obsoleto pelo uso sem critérios (Duran, 2013).

Ao aplicar o conceito de governança no turismo, os resultados também parecem ser diferentes em vários destinos. Entendendo que a governança do turismo é a gestão do processo de turismo, levando os destinos a serem mais ou menos organizados e, portanto, mais ou menos atraentes para os turistas e visitantes, indicando a necessidade de uma maior compreensão sobre esta complexidade. A governança aparece como foco de debate atual na política e turismo, sendo um novo foco de governo que responde à crescente complexidade da gestão de destinos turísticos (Queiroz \& Rastrollo-Horillo, 2015).

A forma e os processos da governança em destinos turísticos será fundamental para alcançar ou não os resultados visados. Assim, o governo tem seu espaço na participação de todas as partes interessadas na busca desses objetivos comuns, em seguida, tornando-se um modelo de governança útil para praticar efetivamente a busca da sustentabilidade nos destinos (Queiroz \& Rastrollo-Horillo, 2015).

No entanto, há um entendimento de que o processo de governança pode ser dirigido não só para as ações, mas também para a compreensão dos resultados alcançados pelos destinos, uma vez que será diferente em cada situação, devido à complexidade e particularidade de cada realidade . É importante visualizar a governança de forma mais ampla, sobre suas formas e meios, mas, ao mesmo tempo, sobre os resultados (Dias \& Pisa, 2013). 


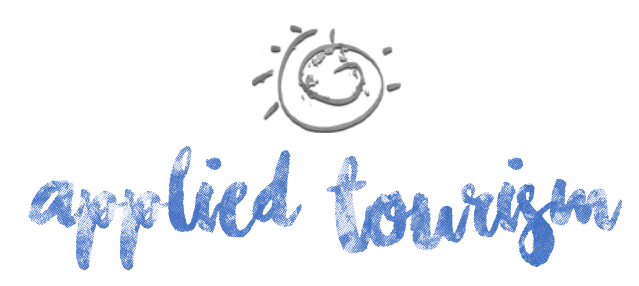

Volume 2, número 1,2017, p. 128-148

Uma das dificuldades ainda relacionadas com a governança, seriam os instrumentos destinados a avaliar seus processos e resultados. Na verdade, ainda há uma falta de instrumentos de avaliação que expõem de uma forma sistemática e oportuna a eficácia das ações do governo e que se baseiam nos princípios da governança pública aplicados na materialização de políticas públicas, seja do Estado ou do governo (Dias \& Pisa, 2015). Alguns autores trabalham com a sugestão de indicadores para a avaliação da governança do turismo (Duran, 2013; Queiroz \& Rastrollo-Horillo, 2015), para a avaliação da governança pública (Dias \& Pisa, 2015), enquanto outros tratam de tipologias de governança de turismo com características diferentes (Hall, 2011), mas ainda não existe uma proposta eficaz para uma ferramenta de avaliação ou a mensuração da governança em destinos turísticos.

Compreendendo a necessidade do desenvolvimento conceitual e prático da hipótese apresentada acima, este trabalho tem como objetivo identificar a literatura no turismo sobre indicadores de governança e tipologias que podem ser a base para a criação de uma ferramenta de avaliação da governança do turismo. Como objetivo geral desta pesquisa procuramos analisar indicadores de avaliação de governança do turismo. Para realizar o objetivo geral, os seguintes objetivos específicos foram listados: Identificar a relação entre as políticas de governança e turismo público; Apresentar os indicadores sugeridos pelos autores da área e áreas afins; Criar uma tabela que resume os vários indicadores de avaliação da governança do turismo; e, Analisar os indicadores de avaliação da governança encontrados na literatura e áreas afins para composição de um quadro conceitual.

\section{GOVERNANÇA E POLIITICAS PÚBLICASDOTURISMO}

O processo de gestão política tem sofrido alterações ao longo das últimas décadas. A participação das comunidades é cada vez mais comum na busca contínua para os objetivos comuns. Este novo processo de governar é reconhecido pelo conceito de governança. Entendendo que a governança é o ato de governar, o poder do governo está cada vez mais 


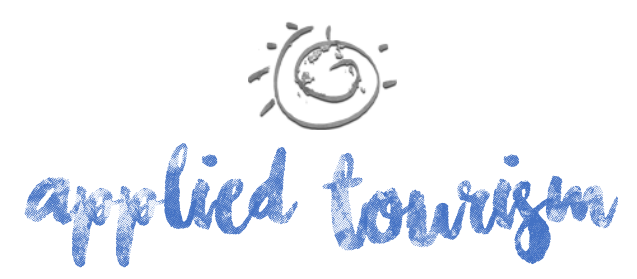

Volume 2, número 1,2017, p. 128-148

acessível à população, uma vez que este processo é aceito por toda a sociedade e, especialmente, pelo governo (Hall, 2011). Historicamente,

O conceito de governança ganhou importância e foi inicialmente concebido como uma abordagem teórica e analítica para compreender as novas formas e práticas de coordenação política e administrativa que têm surgido, relacionados primeiro com a crescente influência política na União Europeia e, em seguida, pelo processo de metropolização (Frey, 2012).

Em relação às implicações, podemos dizer que a governança tem servido como um objeto de estudo em diversas áreas, sendo o termo governança amplamente utilizado em uma variedade de círculos acadêmicos e práticos. Implica nos sistemas de governo, e nas formas pelas quais as sociedades são governadas, regulamentadas ou estimuladas. O termo também sugere a ação coletiva e coordenação (Bramwell, 2011).

O crescimento das cidades, bem como a necessidade de uma maior integração com o surgimento da União Europeia, começaram a intrigar pesquisadores que buscavam entender essas novas práticas (Frey, 2012). É extremamente importante ressaltar o papel da governança neste novo contexto, entendendo que ela é influenciada por inúmeros fatores internos e externos. A governança não pode ser entendida de forma isolada a partir de suas relações com a sociedade, incluindo os grupos sociais que procuram influenciar o processo de governança (Bramwell \& Lane, 2011). Os autores chamam a atenção para o fato de que as vontades dos grupos envolvidos irão influenciar diretamente no processo de gestão e, portanto, deve-se levar todos os aspectos em consideração quando da investigação sobre o governo de uma determinada localidade. É interessante notar que muitos atores podem estar envolvidos, representando as comunidades, empresas ou o terceiro setor (Bramwell \& Lane, 2011).

Esta nova divisão de responsabilidades permite a capacitação dos participantes, previamente passivos, em agentes de governança. Em termos gerais, a governança é uma mudança nos papéis formais de agências governamentais e estruturas contemporâneos. Há também uma mudança na distribuição de responsabilidades entre os grupos públicos, do terceiro setor e da iniciativa privadas (Uzum, 2010). Este novo modelo permite a 


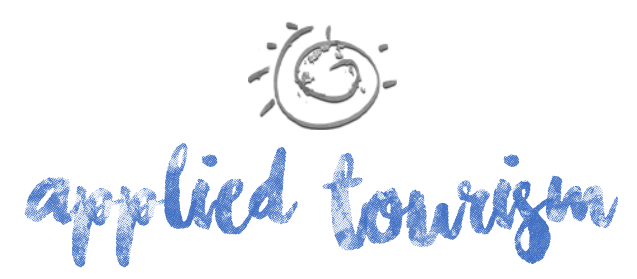

Volume 2, número 1,2017, p. 128-148

popularização das decisões governamentais, e, consequentemente, dos resultados a serem alcançados, muitas vezes buscando objetivos comuns para a maioria dos envolvidos. Este novo conceito pode trazer muitas incertezas, não só teóricas, mas também na prática como

O conceito de governança tornou-se um dos mais importantes, mas também de compreensão mais dúbia, nas políticas públicas. As perspectivas para a cooperação, participação e construção coletiva são acompanhados pelo medo de renúncia pública, regimes oligárquicos e redução da democracia local (Seixas \& Mas, 2010).

Podemos destacar, no entanto, que a principal intenção deste novo processo de gestão é fazer com que as decisões sejam voltadas para o benefício da maioria, procurando em si a regulação de processos e mobilização de ações sociais para produzir uma ordem social envolvendo questões coletivas (Branmwell \& Lane, 2011). Outro aspecto a ser tomado em conta quando falamos de administração é a necessidade de uma observação mais ampla, visando a compreensão dos recursos e processos, mas, ao mesmo tempo, procurando também os resultados obtidos (Dias, 2013). Não podemos dizer que o governo ou o estado não tem mais influência no processo de gestão ou administração, porque ele ainda tem a influência na construção de políticas públicas para o desenvolvimento (Bramwell \& Lane, 2011).

Quanto ao envolvimento do governo no processo de governança, devemos também levar em conta que, em qualquer forma de gestão deve haver uma busca harmoniosa das formas de regulação entre os atores envolvidos, buscando a compreensão de que tanto o setor público e privado precisam de consenso , buscando objetivos comuns para a sociedade como um todo, representada pelo governo, pela comunidade e pelo setor privado (Silva et al, 2012).

O turismo tem sido uma alternativa para vários locais ao redor do mundo na busca pelo seu desenvolvimento econômico, mas ao mesmo tempo, buscando a sustentabilidade ambiental, social e cultural. O processo de gestão de uma zona turística varia de acordo com as peculiaridades regionais, a participação dos seus atores em vários níveis (Zahra, 2011), entre outros aspectos relevantes. Neste sentido, o conceito de governança também 


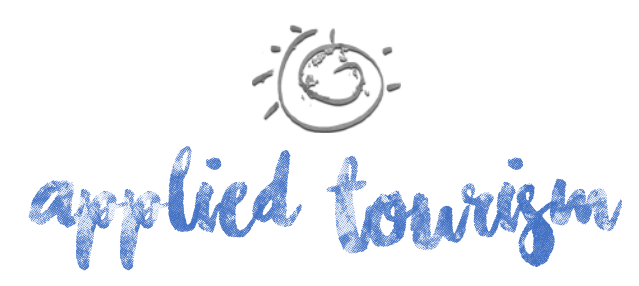

Volume 2, número 1,2017, p. 128-148

está ganhando a atenção no processo de gestão do turismo. O estudo da governança já foi usado como um conceito de pesquisa em turismo desde 1993 (Wang \& Li, 2013). Governança é um conceito chave na política e na política pública e tem sido utilizado mais frequentemente em turismo (Hall, 2011).

As necessidades de um destino turístico para ser capaz de competir em um mercado global e cada vez mais acirrado, faz com que o processo de governança desta atividade vise a competitividade do destino, a fim de maximizar as mudanças necessárias para atingir esse objetivo.

Muitos dos novos tipos de governo têm a intenção e a necessidade de acelerar a competitividade em termos de mudança estrutural e crescimento econômico urbano, onde a cidade é considerada um agente coletivo que deve olhar para os recursos que são escassos (como investimentos econômicos, imagem, turistas, arquitetura espetacular) para garantir um lugar vantajoso no mercado urbano (Seixas \& Mas, 2010).

Sendo o turismo uma atividade que afeta diretamente não só a economia de um lugar, mas também o modo de vida de sua população, o processo de governança deve garantir a inclusão de várias partes interessadas, tais como comunidades, governos e as empresas turísticas, já que esta irá permitir uma maior coesão na gestão e, possivelmente, uma maior relevância mercadológica para o destino (Zahra, 2011).

Sendo a sustentabilidade um dos principais objetivos da gestão do turismo, a governança do turismo também deve ter seus participantes direcionado para ações que a visam, independentemente do contexto geográfico em que estão inseridos. A sustentabilidade exige muitas vezes uma ação coletiva para que isso aconteça, e a governança é a base dessas ações coletivas (Bramwell, 2011). A responsabilidade pela busca da sustentabilidade deve ser um compromisso de todos os níveis envolvidos do governo.

Em cada país, a responsabilidade pelo desenvolvimento do turismo sustentável é dividido por diferentes tipos de atores. As autoridades públicas em todos os níveis, agentes de vendas nacionais e estrangeiros, turistas e comunidade local- são atores na estrutura da governança do turismo e no impacto sobre o desempenho sustentável do turismo (Dinica, 2009). 


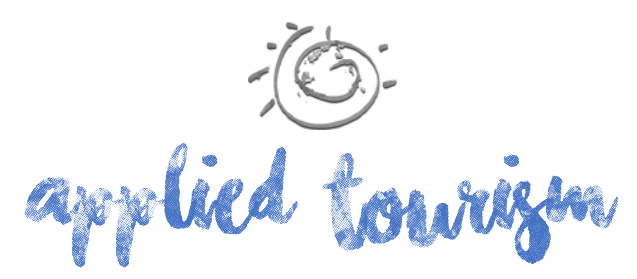

Volume 2, número 1,2017, p. 128-148

A governance directed towards sustainability is the key to the implementation of the governance process and may facilitate democratic processes, direct and provide means for the goals to be achieved. Governance can be changed from time to time, mainly due to political changes and even because of the lessons learned from previous results (Bramwell et al, 2011). The role of residents is extremely important in this context, since they will be directly affected by the results of the planning and execution of actions.

Also embedded in these social representations of tourism planning taken by those in the tourism development sphere are beliefs about how tourist destinations should be managed and about the role that the residents should take in the tourism governance (Moscardo, 2011).

Uma governança orientada para a sustentabilidade é a chave para a implementação do processo de governança e pode facilitar os processos democráticos, direcionar e fornecer os meios para os objetivos serem alcançados. A governança pode ser alterada ao longo do tempo, principalmente devido a mudanças políticas e até mesmo por causa das lições aprendidas com os resultados anteriores (Bramwell et al, 2011). O papel dos moradores é extremamente importante neste contexto, uma vez que eles serão diretamente afetados pelos resultados do planejamento e execução das ações.

Outro personagem importante na governança são as instâncias de governança (IG), que servem para institucionalizar a organização de grupos de interesse comum, neste caso do turismo. Estes grupos podem ser privados, públicos ou mistos, e que podem ser feitas por empresas, associações, agências de desenvolvimento locais e regionais, centros tecnológicos, universidades, entre muitos outros (Sahaidak, 2013; MTur, 2008). Os objetivos comuns serão decisivos para a formação dessa participação, que deve ser igualitária, no sentido da responsabilidade partilhada e também da representatividade.

A identificação dos atores vai determinar os atores interessados no futuro de destino para assegurar a busca dos objetivos comuns. O desafio é o de caracterizar as particularidades desses atores para encontrar o equilíbrio entre as partes, e assegurar a participação efetiva de uma variedade de atores dando-lhes legitimidade e representatividade (Queiros \& Rastrollo-Horillo, 2015). 


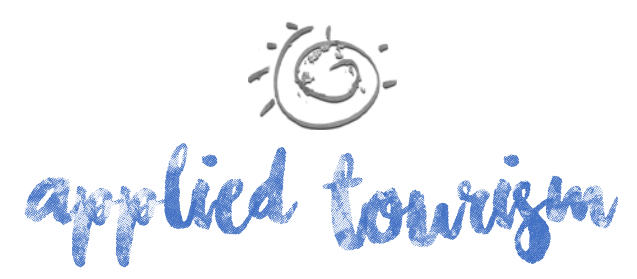

Volume 2, número 1,2017, p. 128-148

Apesar da possibilidade de sucesso na participação de todos os interessados, o turismo sustentável é uma meta muitas vezes bastante difícil de alcançar, uma vez que as suas necessidades perpassam muitos setores e muitos aspectos diferentes, como planejamento, transporte, mudanças climáticas, taxa de emprego e eficiência do desenvolvimento regional (Bramwell, 2011). Mesmo sendo o turismo um fator de mudança para o ambiente e uma forma de buscar o crescimento econômico, o desenvolvimento do turismo sustentável é também um aspecto importante no processo de criação de políticas direcionadas para a sustentabilidade, sendo um aspecto importante para as administrações de destinos turísticos (Hall , 2011).

As políticas públicas são planos, diretrizes, regulamentos, normas e, em especial, as decisões, que expressam a intenção do governo de intervir em uma demanda particular. As políticas públicas são vistas como a solidificação das intenções do Estado para alcançar objetivos coletivos, através de programas governamentais e projetos, tais como a luta contra a pobreza, a criação de novos impostos, controle de poluição, entre outros (Lowi, 1994).

Para o campo do turismo, políticas públicas podem ser entendidas como o sentido dado pelo estado, o governo federal, municipal ou regional para o desenvolvimento do turismo, depois de consultar os representantes do setor turístico e da sociedade (Lohmann \& Panosso Neto, 2008).

O papel das políticas públicas de turismo deve ser o de promover o desenvolvimento harmonioso desta atividade, assim é a responsabilidade do estado organizar uma superestrutura jurídico-administrativa (secretarias e afins) cujo papel é o de planejar e controlar os investimentos feitos pelo estado, que permitem o avanço do setor privado, por meio da construção de equipamentos e prestação de serviços, bem como o papel do governo direcionado para criar mecanismos que garantam o retorno sob a forma de benefícios para a população (Barreto, 2003). 


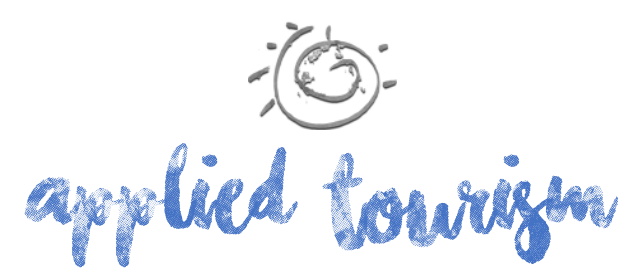

Volume 2, número 1,2017, p. 128-148

Não há dúvida de que a criação de estruturas administrativas é importante para o desenvolvimento do turismo, mesmo porque envolve diretamente a governança, um meio essencial para o equilíbrio da tomada de decisões, destinadas a incentivar e controlar, afim de reduzir as perdas decorrentes do conflito de interesses, inerente ao processo de formulação eimplementação de políticas públicas. Assim, enfatiza-se a importância do papel da governança, entendida aqui como todas as diferentes maneiras de gerenciar problemas de forma integrada entre estado e setor privado, buscando dinamizar o turismo. A governança é um fenômeno mais amplo do que o governo; Abrange instituições governamentais, mas também envolve mecanismos informais, entidades nãogovernamentais, que faz pessoas e organizações adotarem uma determinada conduta, para satisfazer às suas necessidades e responder às suas exigências (Rosenau, 2000).

\section{METODOLOGIA}

Os métodos utilizados para a busca do conhecimento científico irão permitir que determinado estudo tenha credibilidade ou não. A metodologia é um processo de planejamento de ações para a implementação correta de todas as etapas da pesquisa científica. Em relação à natureza deste trabalho, é uma pesquisa aplicada, que busca gerar conhecimentos que possam resolver problemas específicos na prática e pode envolver verdades e interesses locais relacionados a este trabalho. Esta pesquisa é exploratória, pois constrói hipóteses e procura compreender experiência prática através da análise (MatiasPereira, 2013).

É também uma pesquisa qualitativa por causa das percepções obtidas através de instrumentos qualitativos. Em relação à abordagem qualitativa,

No método qualitativo a pesquisa é descritiva, as informações obtidas não podem ser quantificadas. Os dados obtidos são analisados indutivamente. Neste sentido, a interpretação dos fenômenos e significados atribuidos são básicos no processo de pesquisa qualitativa (Matias Pereira, 2013). 


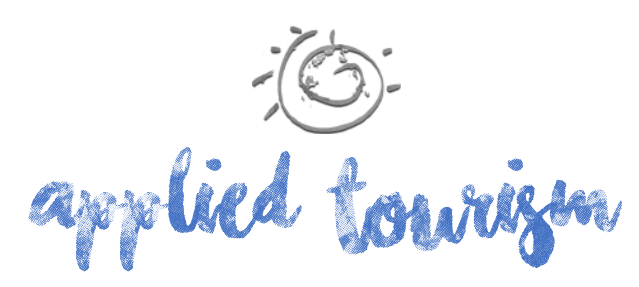

Volume 2, número 1,2017, p. 128-148

Para obter os resultados, foram analisados quatro estudos relacionados com tipologias de governança (Hall, 2011), indicadores de governança pública (Dias \& Pisa, 2015) e governança do turismo (Duran, 2013; Queiroz \& Rastrollo-Horillo, 2015).

\section{SUMÁRIO DOS MODELOS DE GOVERNANÇAPARA DESTINOS TURISTICOS}

\section{Indicadores OMT / Durán (2013)}

Em 2013, a Organização Mundial do Turismo, por meio de suas publicações oficiais, lançou o material intitulado "Governança para o setor do turismo e sua mensuração." O material, de autoria de C. Duran, foi lançado em outubro de 2013, procurando demonstrar a importância da mensuração e análise do turismo, que visa disseminar as ferramentas corretas para que isso aconteça, e para servir como uma plataforma para o desenvolvimento deste campo de trabalho (Duran, 2013). Ao longo do texto, o autor faz uma apresentação de diferentes pontos de vista relacionados com a governança, seguida de uma aproximação conceitual para a governança no setor do turismo e continuando com as orientações gerais para a mensuração da governança no turismo. Segundo o autor, a dificuldade de avaliar a governança é também dada pela multiplicidade de interpretações do termo.

\footnotetext{
Alguém pode facilmente descrever a governança, no entanto, como um conceito mais citado do que compreendido. O melhor que se pode dizer é que ao mencionar o conceito, diferentes atores significam coisas diferentes. O conceito permanece nebuloso, e usado de forma indiscriminada - e muitas vezes erroneamente muitas vezes servindo como um termo genérico. Isto não só priva o termo de utilidade analíica, mas também faz com que seja difícil de compreender e avaliar a sua importância e as implicações para o desenvolvimento (Duran, 2013).
}

Quando aborda a governança no setor do turismo, o autor afirma que o termo tem sido cada vez mais utilizado, sendo um tema relevante eatual que está sendo discutido em fóruns de vários níveis, quer por pesquisadores ou programas de governo, mas ainda é um termo obscuro e não bem definido, cercado por confusão sobre sua definição e suas implicações na atividade (Duran, 2013). 


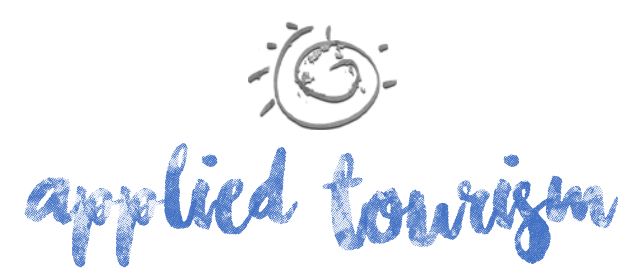

Volume 2, número 1,2017, p. 128-148

A partir destas recomendações, o autor sugere um guia geral para a mensuração da governança no setor do turismo, com duas abordagens. A primeira relacionada com o espaço ocupado pela governança no setor do turismo, avaliando o tamanho da capacidade política do mesmo, sendo a gestão relacionada com a governança. A segunda, avaliar a eficácia das políticas, relacionadas com os resultados obtidos pela governança. Em relação à mensuração, os fatos que podem ser observados são:

- Meios regulamentares ou legais para o exercício da coordenação pública, colaboração e cooperação em nível setorial e estrutural do governo.

- Meios regulamentares ou legais para a formação e desenvolvimento de parcerias público-privadas e relações cooperativas.

- Meios legais e regulamentares para garantir a responsabilidade, transparência e responsabilidade nas relações público-privadas.

- Exercício de coordenação, colaboração e cooperação pública.

- Exercício de coordenação, colaboração e cooperação público-privada (Duran, 2013).

Quanto ao espaço ocupado pela governança do turismo, esta seria definida pela capacidade

e efetividade diretiva, que busquem os seus próprios recursos e tenham graus de importância nos destinos individuais. Ao avaliar a capacidade política, os campos de observação seriam os meios normativos e legais para o exercício da coordenação pública, a cooperação e colaboração nas estruturas do setor e nas estruturas governamentais, com os fatos observáveis sendo os poderes e funções atribuídos à administração do turismo no campo da coordenação, colaboração e cooperação, nos níveis inter e intra-governamentais; Departamentos do setor público com as funções que têm impacto sobre as políticas públicas de turismo, de acordo com o nível de governo; As áreas em que essas funções são compartilhadas ou concomitantes (Duran, 2013).

Avaliando os meios legais e regulamentares para o estabelecimento de colaboração e desenvolvimento de relações público-privadas e cooperativas, pode-se observar os seguintes fatos: estrutura de regulamentação de acordo com o nível de governo e responsáveis pela estruturação e funcionamento de parcerias, a respeito das áreas de aplicação ou de intervenção do estado ou por tipos de serviços públicos de turismo já 


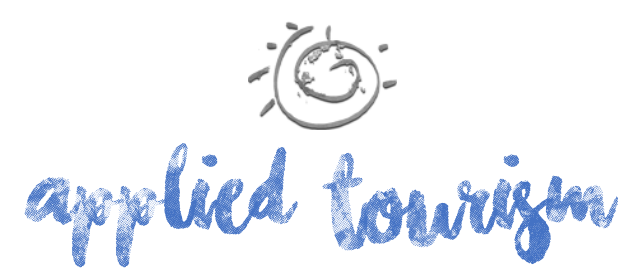

Volume 2, número 1,2017, p. 128-148

existentes ou previstos e; outras formas de colaboração e cooperação (redes de intercâmbio de experiências, observatórios, etc.).

$\mathrm{Na}$ avaliação dos meios legais e regulamentares para garantir a responsabilidade, transparência e responsabilidade nas relações público-privadas, os fatos observáveis são estruturas de colaboração e cooperação público-privada com responsabilidades partilhadas; Mecanismos e instrumentos para a prestação de contas com base em objetivos e resultados; Mecanismos e instrumentos de avaliação de resultados; Instrumentos para promover a empresa responsável.

Quanto à política de eficácia, o autor sugere que deve ser observado práticas governamentais relacionadas com o exercício coordenação, colaboração e cooperação pública, observando os mecanismos existentes de coordenação e instrumentos de cooperação pública usados para buscar objetivos prioritários da política pública de turismo com base na identificação de tipos de mecanismos (legislativo, executivo); o grau de coordenação (níveis); domínios de intervenção (setorial, inter-governamentais); âmbito (nacional, regional, local e internacional) e; procedimentos de prestação de contas com base em objetivos e resultados, e avaliação dos resultados.

O autor conclui afirmando que os indicadores são apenas exemplos, e que podem ser um começo para o desenvolvimento de um sistema de indicadores que enriqueceriam o sistema de informação sobre a governança do turismo e outras áreas comuns de estudo (Duran, 2013).

\section{Indicadores de Governança Pública / IgovP}

O índice de avaliação da governança pública - IgovP foi apresentado pelos autores Oliveira e Pisa (2015), como uma ferramenta a ser utilizada para a mensuração da governança pública com o objetivo de planejamento estatal e a possibilidade de controle social pelo cidadão. 


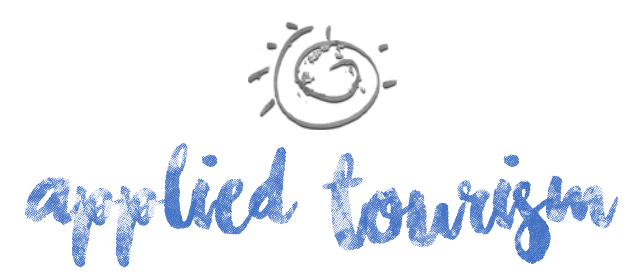

Volume 2, número 1,2017, p. 128-148

O uso de modelos de análise e mensuração detalhada de indicadores que têm como substrato os princípios de governança públicaé uma inovação a fim de ser um mecanismo eficaz para o conhecimento do grau de governança praticada pela União, Distrito Federal e os estados, permitindo o acompanhamento de sua evolução (Oliveira \& Pisa, 2015).

Os autores sugerem indicadores para avaliar a eficácia, transparência e responsabilidade, participação, equidade e legalidade, ética e integridade. Eles finalizam o trabalho, aplicando o IGovP em diferentes estados brasileiros, confirmando a sua eficácia como ferramenta de avaliação para a governança pública.

\section{Tipologias de Governança Turística (Hall, 2011)}

Em 2011, Hall publicou um artigo propondo a definição dos tipos de governança do turismo, apresentando um quadro dos modelos de goverança de destinos turísticos em quatro categorias propostas pelo autor. Depois de discutir a nova governança, ele propõe pontos de análise para tipologias de governança, que eram características; temas de política / governança; ponto de vista político; modelo democrático; foco principal; perfil de atores não-centrais; distinção entre formulação e implementação de políticas; critérios de sucesso; dificuldades de execução; razões para as dificuldades de implementação; soluções para as dificuldades de aplicação; instrumentos de política (Hall, 2011). O autor propõe, em seguida, quatro tipos de governança: hierárquica, redes, comunidade e de mercado.

A governança hierárquica tem pouca discussão na literatura, principalmente no turismo, porque as discussões são mais gerais sobreo papel do governo no turismo, bem como sobre a natureza da intervenção do Estado na atividade (Hall, 2011).

A governança de mercado, apesar da decisão do estado em permitir a ação de mercado na governança, não significa que ela deixará de influenciar o mercado. Em vez de utilizar mecanismos de regulação de impostos, o governo tem a opção de buscar outras formas de interferência, seja através de incentivos financeiros, agentes de educação e até mesmo 


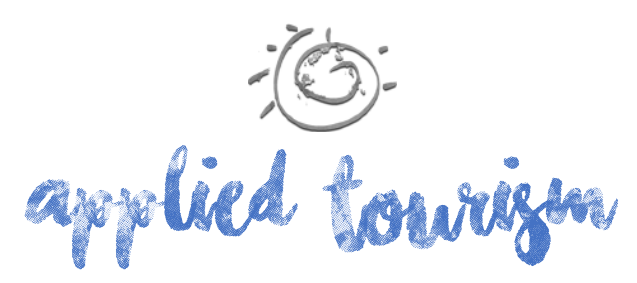

Volume 2, número 1,2017, p. 128-148

eventuais intervenções futuras para incentivar o mercado a seguir em certas direções, geralmente buscando a auto -regulação.

A governança em rede é considerada um meio termo entre a governança hierárquica e governança de mercado. As redes têm sido propostos como meios para a integração de iferentes pontos de vista e perspectivas políticas, embora a capacidade de integração dependa do grau de participação no processo de planejamento e a influência sobre a percepção de ganhos por esta participação. O autor escreve sobre o grau em que estas redes podem agir para alcançar os resultados que visam seus próprios interesses em vez de interesses comuns, tornando-se um desafio na sua utilização como instrumento político, muitas vezes buscando mais resultados econômicos do que a sustentabilidade (Hall, 2011).

Finalmente, a governança comunitária (descentralizada), tem a influência do comunitarismo, propondo que o governo em larga escala é substituído por unidades espaciais em menor escala, com o governo mais próximo da comunidade, bem como uma maior participação da comunidade na criação de políticas públicas.

\section{Dimensões de Governança (Queiroz \& Rastrollo-Horrillo, 2015)}

Em 2015, as autoras Queiroz e Rastrollo-Horillo, em um estudo relacionado com o estado da arte sobre governança, proposta após a avaliação de todo o material pesquisado por elas, propõem três dimensões para avaliar a governança em destinos turísticos. São as dimensões quem, o quê e como.

Na dimensão que, relacionada com os atores envolvidos na governança, as autoras propõem a avaliação da legitimidade e representatividade; capacidade de motivar a participação dos diversos atores; e metas coletivas. Na dimensão o quê, relacionada com o processo e os resultados, a avaliação remete à formação; compromisso; recursos financeiros; tempo para participar; e recursos tecnológicos. Finalmente, na dimensão como, também relacionada com os processos, as autoras sugerem avaliar a capacidade de fazer as regras respeitadas; 


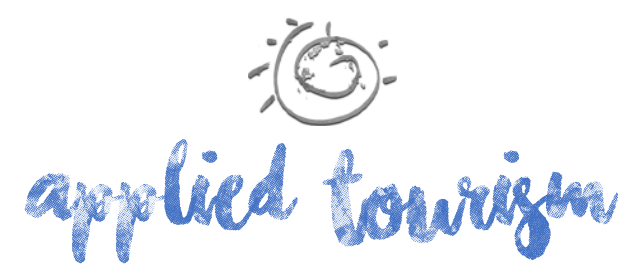

Volume 2, número 1,2017, p. 128-148

mecanismos de controle e sanções; capacidade de prestação de contas; instrumentos: as redes e coordenação de múltiplos níveis (nacional, regional, local); Web sites, fóruns, conselhos, planejamento; aspectos regulatórios, incentivos; órgãos de controle; voto, consultas populares; calendário anual de atividades (Queiroz \& Rastrollo-Horillo, 2015).

Estas sugestões ainda carecem de um instrumento de aplicação para verificar a eficácia das propostas feitas pelas autoras.

\section{CONSIDERAÇÕES FINAIS}

Após a apresentação deste quatro estudos, a construção de uma tabela que poderia sintetizar a informação foi necessária, visando comparar as diferentes ferramentas e indicadores para verificação futura dos aspectos comuns e / ou para complementar aspectos excluídos nestes estudos (quadro 1). 


\section{apyctied townigh}

Volume 2, número 1,2017, p. 128-148

Quadro 1 - Quadro comparativo adaptados dos autores (Queiroz, 2015; WTO, 2013; Hall, 2011; Oliveira, Pisa, 2015)

\begin{tabular}{|c|c|c|c|c|}
\hline Autor & Hall, 2011 & Duran, 2013 & Queiroz; Rastrillo-Horrillo, 2015 & Oliveira; Pisa, 2015 \\
\hline $\begin{array}{l}\text { Objeto } \\
\text { de } \\
\text { Estudo }\end{array}$ & Tipologias de governança & Indicadores de governança & Dimensões de governança & Indicadores de Governança Pública \\
\hline Divisões & $\begin{array}{l}\text { Governança Hierárquica } \\
\text { Governança de Comunidades } \\
\text { Governança de Redes } \\
\text { Governança de Mercados }\end{array}$ & $\begin{array}{l}\text { Capacidade Diretiva } \\
\text { Efetividade Diretiva }\end{array}$ & $\begin{array}{l}\text { Dimensão Quem } \\
\text { Dimensão Que } \\
\text { Dimensão Como }\end{array}$ & $\begin{array}{l}\text { Efetividade } \\
\text { Transparência e Prestação de Contas } \\
\text { Participação } \\
\text { Equidade } \\
\text { Legalidade, ética e integridade }\end{array}$ \\
\hline $\begin{array}{l}\text { Fatores } \\
\text { de } \\
\text { análise }\end{array}$ & $\begin{array}{l}\text { - Tipos de Classificação e } \\
\text { - Taracterísticas } \\
\text { - Temas políticos / governança } \\
\text { - Política de perspectiva } \\
\text { - Modelo utilizado de democracia } \\
\text { - Foco principal } \\
\text { - Atores } \\
\text { - Distinção entre formulação e } \\
\text { implementação de políticas } \\
\text { - Critérios de sucesso } \\
\text { - Falhas de implementação / } \\
\text { déficits } \\
\text { - Motivos para implementação de } \\
\text { lacunas / déficits } \\
\text { - Solução para implementação de } \\
\text { lacunas / déficits } \\
\text { - Instrumentos de política primária. }\end{array}$ & $\begin{array}{l}\text { - Capacidade institucional das Agências } \\
\text { de turismo público para coordenação, } \\
\text { colaboração e cooperação pública } \\
\text { - Capacidade institucional das ptas para } \\
\text { colaboração público-privada } \\
\text { - Capacidade institucional das ptas para } \\
\text { a transparência } \\
\text { - Grau de responsabilidade na gestão } \\
\text { do turismo } \\
\text { - Grau de transparência e prestação de } \\
\text { contas em colaborações público- } \\
\text { privadas } \\
\text { - Grau de participação não } \\
\text { governamental nas decisões sobre o } \\
\text { turismo } \\
\text { - Indice de efetividade diretiva das } \\
\text { ptas. }\end{array}$ & $\begin{array}{l}\text { - Quem-legitimidade e } \\
\text { representatividade; capacidade para } \\
\text { motivar a participação da variedade } \\
\text { de atores; metas coletivas } \\
\text { - Que - Formação; compromisso; } \\
\text { recursos financeiros; tempo para } \\
\text { participar; recursos tecnológicos. } \\
\text { - Como-Capacidade para fazer as } \\
\text { regras serem respeitadas; } \\
\text { Mecanismos de controle e sanções; } \\
\text { Capacidade de prestação de contas; } \\
\text { Instrumentos: redes e coordenação } \\
\text { multinível (nacional, regional, local), } \\
\text { DMo; Web sites, Foruns, Conselhos, } \\
\text { Juntas, Planejamento; Aspectos } \\
\text { normativos, incentivos; Agências de } \\
\text { controle; Voto, consultas populares; } \\
\text { Calendário nual de atividades. }\end{array}$ & $\begin{array}{l}\text {-Efetividade - Renda média domiciliar } \\
\text { per capita percentual; Índice de } \\
\text { Desenvolvimento Humano Municipal } \\
\text { (IDH - M). } \\
\text {-Transparência e Prestação de Contas } \\
\text { - Índice de Transparência. } \\
\text {-Participação - Percentual de } \\
\text { Eleitorado Votos Válidos versus } \\
\text { Eleitores aptos percentual 1o. Turno; } \\
\text { Taxa de participação em Conselhos } \\
\text { Nacionais e Estaduais. } \\
\text {-Equidade- Índice de Gini da } \\
\text { distribuição do rendimento mensal } \\
\text { das pessoas de } 10 \text { anos ou mais de } \\
\text { idade, ocupadas na semana de } \\
\text { referência, com rendimento de } \\
\text { trabalho; Taxa de analfabetismo } \\
\text {-População de } 15 \text { ou mais por } \\
\text { unidade da Federação segundo } \\
\text { região; Taxa de desemprego: } \\
\text { percentual da população de } 16 \text { anos } \\
\text { e mais, economicamente ativa, } \\
\text { desocupada. }\end{array}$ \\
\hline
\end{tabular}




\section{aypilied towrigh}

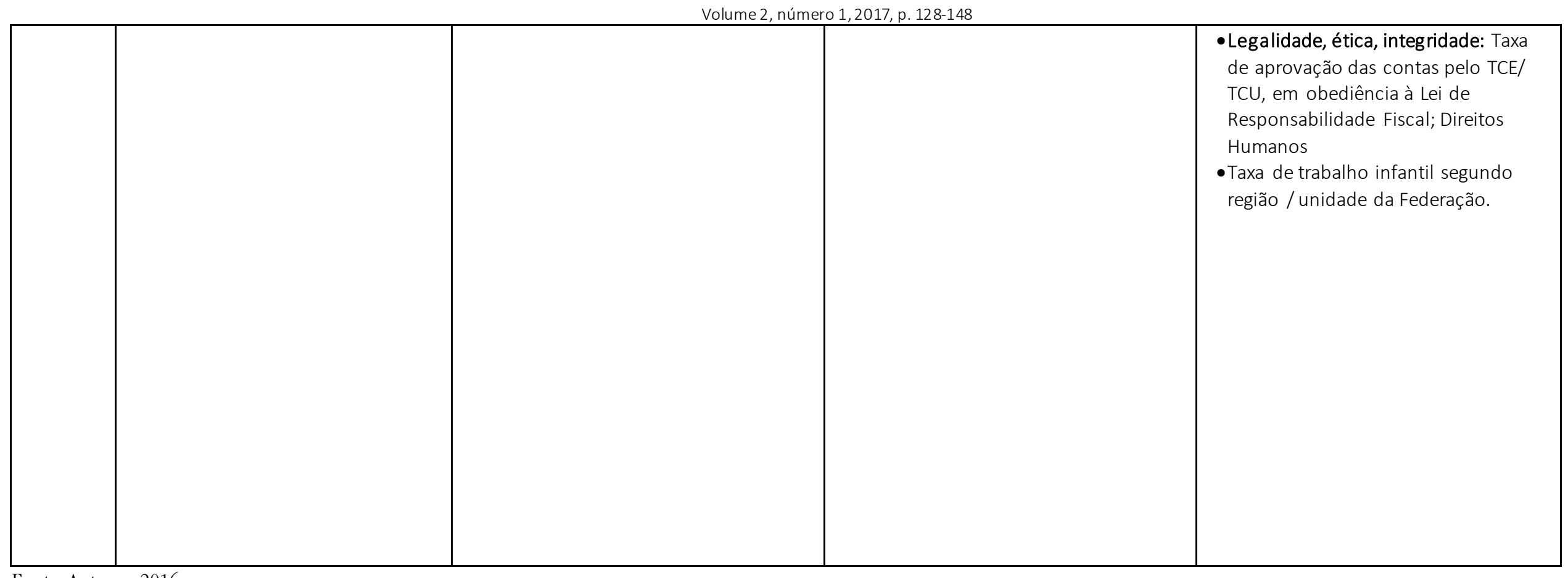

Fonte: Autores, 2016. 


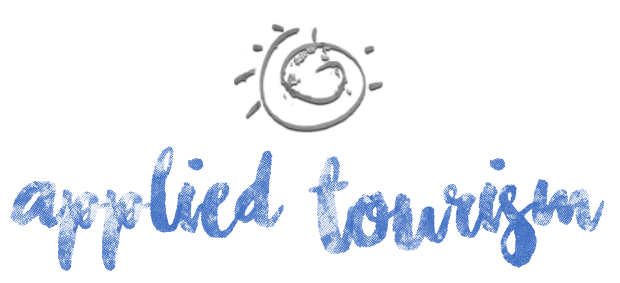

Volume 2, número 1, 2017, p. 128-148

Brasil. Secretaria de Planejamento e Investimentos Estratégicos. (2010). Indicadores de programas guia metodológico. Brasília: Ministério do Planejamento, Orçamento e Gestão (MPOG).

Dias, P. P. (2013) O desenvolvimento doecoturismo em Pernambuco: Uma análise sob a ótica da governança. Universidade Federal Rural de Pernambuco. Recife.

Dinica, V. (2009) Governance for sustainable tourism: a comparison of international and dutch visions. Journal of Sustainable Tourism. Vol 17, n.5. Sep., $45-56$.

Duran, C. (2013). Governance for the Tourism Sector and its measurement. UNWTO Statistics and TSA Issue Paper Series.

Frey, K. (2012) Abordagens de governança em áreas metropolitanas da América Latina: avanços e entraves. URBE. Revista Brasileira de Gestão Urbana. Vol 4, n.1. Curitiba, jan/jun, 87-102.

Hall, C. M. (2011) Policy Learning and policy failure in sustainable tourism governance: from first and second order to third order change? Journal of Sustainable Tourism. Vol 19. MayJune, 649-671.

Hall, C. M. (2011) A typology of governance and its implications for tourism policy analysis. Journal of Sustainable Tourism. Vol 19, may/june, 437-457.

Lohmann, G.; Panosso Neto, A. (2008) Teoria do turismo: conceitos, modelose sistemas. São Paulo: Aleph.

Matias-Pereira, J. (2012) Manual de Metodologia da pesquisa científica. São Paulo: Atlas.

Moscardo, G. (2011) Exploring Social representations of tourism planning: issues for governance. Journal of Sustainable Tourism. Vol. 19. May-June, 423-436.

Oliveira, A. G.,\& Pisa, B. J. (2015) IGovP:índice de avaliação da governança pública - instrumento de planejamento do Estado e de controle social pelo cidadão. Revista de Administração Pública - Rio de janeiro 49 (5): 1263-1290, set/out.

Pechlaner, H., Volgger, M., \& Herntrei, M. (2012). Destination management organizations as interface between destination governance and corporate governance. Anatolia - An International Journal of Tourism and Hospitality Research. Vol. 13, n.2. August, 151-168.

Queiroz, F., \& Rastrollo-Horillo, M. (2015) El estado del arte en gobernanza de destinos turísticos. Tourism and Management Studies, 11, vol 2, 47-55.

Rosenau, J. N. Governança, ordem e transformação na política mundial. In: J. N. Rosenau, \& E. Czempiel. (2000) Governança sem governo: ordem e transformação na política mundial. Brasilia: Ed. Unb e São Paulo: Imprensa Oficial do Estado, 2000. p. 11-46.

Sahaidak, A. (2013) A implantação doprojeto turístico Rota dos Tropeiros (PR): Políticas Públicas e Governança. Universidade Estadual de Ponta Grossa. Mestrado em Gestão do Territónio. Ponta Grossa. 


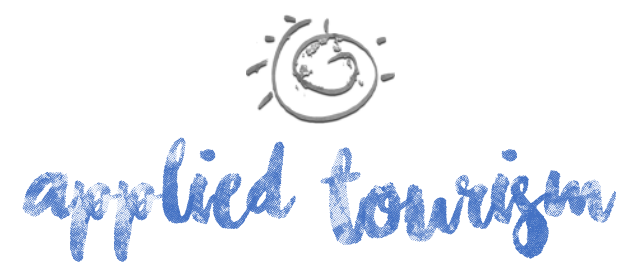

Volume 2, número 1,2017, p. 128-148

Santos, M. H.C. (1997). Governabilidade, governança e democracia: criação da capacidade governativa e relações executivo-legislativo no Brasil pós-constituinte. In:DADOS-Revista de Ciências Sociais. Rio de Janeiro, v. 40, n. 3. p. 335-376.

Seixas, J., \& Mas, A. A. I. (2010) Urban Governance in the South of Europe: cultural identities and global dillemmas. Análise Social. N.197. Lisboa, 771-787.

Silva, L. F., Mantovaneli Jr, O., \& Sampaio, C. A. C. (2012). Gobernanza y Territorialidad em el desarrollo turístico regional: el caso del Oktoberfest en Blumenau - Brasil. Estudios $Y$ Perspectivasen Turismo. Vol. 21, n.6. Buenos Aires, 1369-1388.

Wang, J., \& Li, T. ( 2013) Review on Tourist Destination Governance in Foreign Countries. Tourism Tribune. Vol 28, n6, 15-25.

Zahra, A. L. (2011) Rethinking regional Tourism governance: the principle of subsidiarity.Journal of Sustainable Tourism. Vol. 19. N. 4-5, May, 535-552. 